\title{
Polyol-pathway-dependent disturbances in renal medullary metabolism in experimental insulin-deficient diabetes mellitus in rats
}

\author{
F. Palm ${ }^{1,2}$ • P. Hansell ${ }^{1}$ G. Ronquist ${ }^{3}$ A. Waldenström ${ }^{4}$ - P. Liss $^{2}$ • P.-O. Carlsson ${ }^{1,5}$ \\ ${ }^{1}$ Department of Medical Cell Biology, Biomedical Center, Uppsala University, Uppsala, Sweden \\ 2 Department of Diagnostic Radiology, Uppsala University, Sweden \\ ${ }^{3}$ Department of Clinical Chemistry, Uppsala University, Sweden \\ ${ }^{4}$ Department of Cardiology, Umeå Hospital, Umeå, Sweden \\ ${ }^{5}$ Department of Medical Sciences, Uppsala University, Sweden
}

\begin{abstract}
Aims/hypothesis. The renal medullary region is particularly vulnerable to reduced oxygen concentration because of its low blood perfusion and high basal oxygen consumption. This study investigated renal metabolic changes in relation to the previously observed decreased oxygen tension in streptozotocin-induced diabetic rats.

Methods. Blood perfusion, oxygen tension and consumption, interstitial $\mathrm{pH}$, and glycolytic and purinebased metabolites were determined in the renal cortex and the medulla of non-diabetic and diabetic animals by, respectively, laser Doppler flowmetry, oxygen and $\mathrm{pH}$ microelectrodes, and microdialysis. The importance of increased polyol pathway activity for the observed alterations was investigated by daily treatment with the aldose reductase inhibitor AL-1576 throughout the course of diabetes.
\end{abstract}

Results. The diabetes-induced decrease in renal oxygen tension, due to augmented oxygen consumption, did not result in manifest hypoxia in either the cortical or the medullary region, as evaluated by microdialysis measurements of purine-based metabolites. The profound alterations in medullary oxygen metabolism were, however, associated with an increased lactate : pyruvate ratio and a concomitantly decreased $\mathrm{pH}$. Notably, the renal medullary changes in oxygen tension, oxygen consumption, lactate : pyruvate ratio and $\mathrm{pH}$ were preventable by inhibition of aldose reductase.

Conclusions/interpretation. Substantial metabolic changes were observed in the renal medulla in diabetic animals. These disturbances seemed to be mediated by increased polyol pathway activity and could be prevented by inhibition of aldose reductase.

Keywords Aldose reductase $\cdot$ Kidney $\cdot$ Metabolism · Microcirculation
Received: 22 December 2003 / Accepted: 1 April 2004

Published online: 30 June 2004

(C) Springer-Verlag 2004

F. Palm (๘)

Department of Medical Cell Biology, Biomedical Center, Uppsala University, Box 571, 75123 Uppsala, Sweden

E-mail: Fredrik.Palm@medcellbiol.uu.se

Tel.: +46-18-4714156, Fax: +46-18-4714938

Abbreviations: DAG, 1,2-diacyl-sn-glycerol - GFR, glomerular filtration rate $\cdot \mathrm{PKC}$, protein kinase $\mathrm{C} \cdot \mathrm{ROS}$, reactive oxygen species $\cdot \mathrm{STZ}$, streptozotocin

\section{Introduction}

Renal complications of diabetes mellitus are a major cause of morbidity and mortality. The DCCT has demonstrated that the degree of hyperglycaemia is an important predictor of subsequent diabetic renal complications [1]. However, the exact processes mediating the influence of hyperglycaemia on renal function remain largely unknown. In other organs known to be vulnerable to complications of diabetes mellitus, i.e. retina and nerves, changes in the microcirculation, oxygen tension and cellular metabolism have been thoroughly studied and seem to be crucial for the progression of organ failure $[2,3,4]$. The majority of studies on diabetic nephropathy have been conducted in vitro and/or have focused on glomerular changes. In the kidney, the medul- 
lary region is particularly vulnerable to decreased oxygen concentration because of its low blood perfusion and high basal oxygen consumption $[5,6]$. Even during normal situations, the renal medulla works at the threshold of hypoxia $[5,6]$ and has an oxygen extraction from the blood of about $90 \%$ [7].

We have recently shown that reactive oxygen species (ROS) play an important role in the development of hyperglycaemia-induced alterations in renal oxygen metabolism [8]. Oxidative stress, closely associated with excessive formation of ROS, was predominantly found in the renal medulla and was related to increased oxygen consumption and decreased tissue oxygen tension. Increased formation of ROS has been shown to activate numerous known pathways contributing to the development of diabetes complications, including increased flux through the polyol pathway [9]. The contribution of the polyol pathway to the development of neuropathy and retinopathy has been thoroughly investigated $[10,11,12]$, but little is known about the influence on renal microcirculation and metabolism.

The present study was designed to investigate the influence of diabetes-induced changes in oxygen tension and consumption in relation to regional renal metabolism in rats. In a second set of experiments, the putative role of the polyol pathway for hyperglycaemia-induced alterations in renal metabolism was studied.

\section{Materials and methods}

Animals. Male Wistar-Furth rats, weighing 280-300 g, were purchased from M\&B (Ry, Denmark). They had free access to water and rat chow (R3; Ewos, Södertälje, Sweden) throughout the study. The animal ethics committee of Uppsala University approved all experiments.

The animals were divided into four experimental groups: (i) non-diabetic control animals; (ii) diabetic animals; (iii) nondiabetic animals treated with an aldose reductase inhibitor throughout the 4-week experimental period; and (iv) diabetic animals treated with the same aldose reductase inhibitor.

Treatment protocol. Diabetes mellitus was induced by an intravenous injection of streptozotocin (STZ, $45 \mathrm{mg} / \mathrm{kg}$; SigmaAldrich, St. Louis, Mo., USA). One group of diabetic animals was given the aldose reductase inhibitor AL-1576, spiro(2,7-difluoro-9H-fluoren-9,4'-imidazolidine) $2^{\prime}, 5^{\prime}$-dione,

( $0.02 \mathrm{mmol} / \mathrm{kg}$ body weight; Alcon, Forth Worth, Tex., USA) once daily by oral gavage (08.00 hours), starting $24 \mathrm{~h}$ before the induction of diabetes. Blood glucose concentrations were determined from blood samples obtained from the cut tip of the tail (MediSense, Bedford, Mass., USA). The animals were considered diabetic if blood glucose concentrations increased to $\geq 15 \mathrm{mmol} / \mathrm{l}$ within $48 \mathrm{~h}$ of STZ injection. The blood glucose concentrations and the body weights were monitored weekly throughout the course of the study.

Surgical procedures. The animals were anaesthetised with an intraperitoneal injection of thiobutabarbital (Inactin; Research Biochemicals International, Natick, Mass., USA; non-diabetic animals: $120 \mathrm{mg} / \mathrm{kg}$ body weight, diabetic animals: $80 \mathrm{mg} / \mathrm{kg}$ body weight), placed on a servo-controlled heating pad maintained at $37{ }^{\circ} \mathrm{C}$ and tracheostomised. Polyethylene catheters were placed in both femoral arteries and in the right femoral vein. One arterial catheter was used to monitor blood pressure (Statham P23dB; Statham Laboratories, Los Angeles, Calif., USA), whereas the other was used for blood sampling. Saline was infused into the vein to compensate for body fluid loss. The urinary bladder was catheterised to allow urinary drainage. The left kidney was exposed by a left subcostal flank incision, immobilised in a plastic cup and embedded in cotton wool soaked in saline. The surface of the kidney was covered with paraffin oil. The left ureter was catheterised for urine collection. Following surgery, the animals were subjected to measurements of regional renal blood flow and oxygen tension, to $\mathrm{pH}$ measurements or to microdialysis.

Regional renal oxygen tension, blood flow and tissue $\mathrm{pH}$ measurements. The animals were allowed a 60-min equilibration period, which was followed by a period of $60 \mathrm{~min}$ to estimate the glomerular filtration rate (GFR) by determining inulin clearance. For this purpose, ${ }^{3} \mathrm{H}$-inulin $(185 \mathrm{kBq} / \mathrm{ml}$; American Radiolabeled Company, St. Louis, Mo., USA) dissolved in saline was initially given as a bolus dose of $185 \mathrm{kBq}$ and then infused intravenously $\left(5 \mathrm{ml} \cdot \mathrm{kg}^{-1} \cdot \mathrm{h}^{-1}\right)$. Urine and arterial blood samples were taken for subsequent analyses. Renal oxygen tension was thereafter measured using modified Clark-type microelectrodes (4-6 $\mu$ m o.d.; Unisense, Aarhus, Denmark) [13]. The electrodes were two-point calibrated in water, saturated with either $\mathrm{Na}_{2} \mathrm{~S}_{2} \mathrm{O}_{5}$ or with air at $37{ }^{\circ} \mathrm{C}$. Microelectrodes were inserted into the renal tissue using a micromanipulator. A linear correlation was obtained between oxygen tension and the electric current. The latter was measured using picoamperemeters (University of Aarhus, Denmark). Oxygen tension measurements were performed at $1-\mathrm{mm}$ increments from the renal cortex to the inner part of the medulla, at a total depth of $5 \mathrm{~mm}$ from the renal surface. This procedure was repeated a minimum of five times in each left kidney. The averages for each respective depth from one animal were then considered as one experiment in the statistical analysis. Following the oxygen tension measurements, regional renal blood flow was measured by laser Doppler flowmetry (probe 0.45 mm, PF 4001-2; Perimed, Stockholm, Sweden), by advancing the probe into the renal tissue in the same manner as the oxygen tension electrodes. Tissue $\mathrm{pH}$ was measured in the renal cortex $(1 \mathrm{~mm}$ from the renal surface) and in the renal medulla (4 $\mathrm{mm}$ from the renal surface) with $\mathrm{pH}$ microelectrodes (PH20; Unisense) connected to a $\mathrm{pH}$ meter (PHM240; Radiometer, Aarhus, Denmark). The electrodes were calibrated at $37{ }^{\circ} \mathrm{C}$ before and after every experiment, using five standard buffers with $\mathrm{pH} 9.088 \pm 0.010,7.386 \pm 0.010,6.974 \pm 0.010,6.841 \pm 0.010$ and $4.020 \pm 0.010$ (Radiometer). The sensitivity of these electrodes has previously been shown to be $0.003 \mathrm{pH}$ units, and the drift to be below $0.005 \mathrm{pH}$ unit/h [14]. The $\mathrm{pH}$ electrodes (tip o.d., $20 \mu \mathrm{m}$; measuring distance, $100 \mu \mathrm{m}$ ) were inserted into the tissue by the same procedure as described above for oxygen sensors. A stable reading was usually obtained within the first 2 minutes of insertion into the renal tissue. After the experiment, the kidney was dissected to verify the sites of oxygen tension, blood flow or $\mathrm{pH}$ measurements. Any site of measurement found to be incorrectly located was excluded. The distances from the renal surface to the border between the cortex and the medulla and between the renal surface and the urinary calyces were determined using a stereomicroscope with a ruler.

Microdialysis. A small piece of the left renal capsule was removed and two microdialysis probes (CMA/12, cut-off $20 \mathrm{kDa}$, $0.5 \mathrm{~mm}$ o.d., length $1 \mathrm{~mm}$; CMA/Microdialysis, Stockholm, Sweden) were inserted into the renal cortex and the medulla ( $1 \mathrm{~mm}$ and $4.5 \mathrm{~mm}$, respectively, from the renal surface). The 
probes were connected to a microdialysis pump (CMA/102; CMA/Microdialysis) and perfused $(0.5 \mu \mathrm{l} / \mathrm{min})$ with buffer solutions (containing $\mathrm{Na}_{2} \mathrm{HPO}_{4}$; pH 7.40; osmolarity 300 mosmol/kg $\mathrm{H}_{2} \mathrm{O}$ for cortex and $600 \mathrm{mosmol} / \mathrm{kg} \mathrm{H}_{2} \mathrm{O}$ for medulla). After an initial 2-h equilibration period, the dialysate was sampled on ice. Blood and urine samples were collected for GFR measurements (see above).

In vitro recovery. The microdialysis probe was perfused at $0.5 \mu \mathrm{l} / \mathrm{min}$, with the same phosphate buffers as used in vivo, at $37^{\circ} \mathrm{C}$ in known concentrations of lactate $(625,1250,2500$ and $5000 \mu \mathrm{mol} / \mathrm{l})$, pyruvate $(125,250,500$ and $1000 \mu \mathrm{mol} / \mathrm{l})$, glucose $(3.12,6.25,12.5$ and $25.0 \mathrm{mmol} / \mathrm{l})$, adenosine, inosine and hypoxanthine $(12,25,50$ and $100 \mu \mathrm{mol} / \mathrm{l})$ dissolved in the same phosphate buffers.

Analysis of microdialysis samples. Concentrations of lactate, pyruvate, adenosine, inosine and hypoxanthine were analysed using an HPLC technique with UV detection [15, 16]. Glucose concentrations were measured with CMA/600 (CMA/Microdialysis), which uses enzymatic reagents and absorbance measurements at $546 \mathrm{~nm}$.

Measurements of blood and urine parameters. The radioactivity of ${ }^{3} \mathrm{H}$-inulin in plasma $(10 \mu \mathrm{l})$ and urine $(1 \mu \mathrm{l})$ was measured by liquid scintillation. The GFR was then calculated as the clearance of ${ }^{3} \mathrm{H}$-inulin. The urine volumes were measured gravimetrically; the osmolality was measured using a freezing point technique (Model 3MO; Advanced Instruments, Mass., USA); and the urinary sodium and potassium concentrations were measured by flame photometry (IL543; Instrumentation Lab, Milan, Italy). At the end of each experiment, a blood sample was collected for analysis of haematocrite and blood gases. Animals with a mean arterial blood pressure of $<85 \mathrm{~mm} \mathrm{Hg}$, a $\mathrm{pH}$ of $<7.3$, a $\mathrm{pO}_{2}$ of $<10 \mathrm{kPa}$, a $\mathrm{pCO}_{2}$ of $>6.8 \mathrm{kPa}$, or haematocrite of $<40 \%$ were excluded from the study.

Isolation of renal cells and measurement of in vitro oxygen consumption. The buffer solution had, if not stated otherwise, the following composition in mmol/l: $113.0 \mathrm{NaCl}, 4.0 \mathrm{KCl}, 27.2$ $\mathrm{NaHCO}_{3}, 1.0 \mathrm{KH}_{2} \mathrm{PO}_{4}, 1.2 \mathrm{MgCl}_{2}, 1.0 \mathrm{CaCl}_{2}, 10.0$ HEPES, 0.5 $\mathrm{Ca}$ lactate, 2.0 glutamine. The buffer osmolality was adjusted to $298 \pm 2 \mathrm{mosmol} / \mathrm{kg} \mathrm{H}_{2} \mathrm{O}$ as estimated with a freezing-point osmometer (Model 3MO; Advanced Instruments), and the $\mathrm{pH}$ was adjusted to 7.40. Streptomycin (VWR International, Stockholm, Sweden) was added, resulting in a final concentration of $50 \mathrm{U} / \mathrm{ml}$. For non-diabetic rats, the buffer contained $5.8 \mathrm{mmol} / \mathrm{l}$ glucose, and for diabetic animals the buffer contained $23.2 \mathrm{mmol} / \mathrm{l}$ glucose (similar to the blood glucose concentrations in the latter animals). The renal cells were isolated as previously described $[8,17,18]$. In brief, the rats were anaesthetised with thiobutabarbital, the kidneys were excised and the renal capsule was removed. The kidneys were placed on ice and the cortex and outer medulla were dissected under a stereomicroscope. Kidneys from two rats of the same group were pooled to increase the tissue material. The renal tissue was minced through a metallic mesh-strainer and immediately placed in an ice-cooled buffer solution (see above) containing $0.05 \%$ (w/v) collagenase (Sigma-Aldrich). Thereafter, the minced tissue was incubated at $37{ }^{\circ} \mathrm{C}$, while the buffer was equilibrated with $95 \% \mathrm{O}_{2} / 5 \% \mathrm{CO}_{2}$. At least once every 5 minutes, the buffer-tissue solution was stirred manually. After incubation, the cell suspension was cooled on ice and filtrated through graded filters with pore sizes of $180,75,53$ and $38 \mu \mathrm{m}$ respectively. After filtration, the cells were pelleted using a low centrifugal force (100 $g, 4 \mathrm{~min})$ and resuspended in a collagenase-free buffer. The rinsing procedure was repeated three times to ensure that no collagenase remained in the final cell suspension.

Oxygen consumption was measured as previously described [8, 18]. In brief, a custom-made thermostatically controlled $\left(37^{\circ} \mathrm{C}\right)$ gas-tight plexi-glass chamber with a total volume of $1.100 \mathrm{ml}$ was used. The chamber was continuously stirred with an air-driven magnetic stirrer. A modified Unisense 500 oxygensensing electrode, calibrated with air-equilibrated buffer solution set to $228 \mu \mathrm{mol} / 1 \mathrm{O}_{2}$ and $\mathrm{Na}_{2} \mathrm{~S}_{2} \mathrm{O}_{5}$-saturated buffer set to zero, was used to measure oxygen consumption. After the calibration, $100 \mu \mathrm{l}$ of cell suspension was injected into the chamber and the rate of oxygen disappearance was recorded. At the end of each experiment, a 100- $\mu$ l sample was taken to determine the protein concentration using DC Protein Assay (Bio-Rad Laboratories, Hercules, Calif., USA). The oxygen consumption was calculated as the disappearance rate of oxygen adjusted for protein concentration.

In all experimental groups, measurements were conducted on both cortical and medullary cells with and without pretreatment with $1 \mathrm{mmol} / \mathrm{l}$ ouabain. Due to the very low number of medullary cells obtained during the isolation process, medulla from four animals were pooled in order to increase the consumption rate to adequate levels.

Statistical analysis. All values are given as means \pm SEM. Multiple comparisons between data were performed by ANOVA followed by Fisher's protected least significant difference test (Statview; Abacus Concepts, Berkeley, Calif., USA). A $p$ value of $<0.05$ was considered statistically significant.

\section{Results}

Animals given STZ decreased in body weight by $\sim 20 \%$ during the first 2 weeks. Thereafter, the body weight of these animals remained fairly constant until the final experiments 4 weeks later (Table 1). Treat-

Table 1. Body weights, blood glucose concentrations, mean arterial blood pressures, haematocrite, and arterial blood pH in non-diabetic and diabetic animals with and without treatment with the aldose reductase inhibitor AL-1576 throughout the 4-week experimental period

\begin{tabular}{lcccc}
\hline & $\begin{array}{l}\text { Control } \\
(n=32)\end{array}$ & $\begin{array}{l}\text { Control + AL-1576 } \\
(n=20)\end{array}$ & $\begin{array}{l}\text { Diabetes 4 weeks } \\
(n=30)\end{array}$ & $\begin{array}{l}\text { Diabetes 4 weeks + AL-1576 } \\
(n=29)\end{array}$ \\
\hline Body weight $(\mathrm{g})$ & $311 \pm 3$ & $320 \pm 10$ & $243 \pm 4^{\mathrm{a}}$ & $247 \pm 4^{\mathrm{ac}}$ \\
Blood glucose (mmol/l) & $5.9 \pm 0.1$ & $5.9 \pm 0.1$ & $25.1 \pm 0.6^{\mathrm{a}}$ & $23.3 \pm 0.6^{\mathrm{abc}}$ \\
Mean arterial blood pressure (mm Hg) & $108 \pm 2$ & $115 \pm 2$ & $108 \pm 2$ & $109 \pm 2$ \\
Haematocrite $(\%)$ & $45 \pm 1$ & $44 \pm 1$ & $45 \pm 1$ & $45 \pm 1$ \\
Blood pH & $7.34 \pm 0.01$ & $7.32 \pm 0.01$ & $7.35 \pm 0.0$ & $7.33 \pm 0.01$ \\
\hline
\end{tabular}

Results are presented as means \pm SEM. ${ }^{\mathrm{a}} p<0.05$ vs control group; ${ }^{\mathrm{b}} p<0.05$ vs untreated 4-week-diabetic animals; ${ }^{\mathrm{c}} p<0.05 \mathrm{vs}$ treated control animals. All comparisons were made using ANOVA and, when appropriate, Fisher's protected least significant difference test 


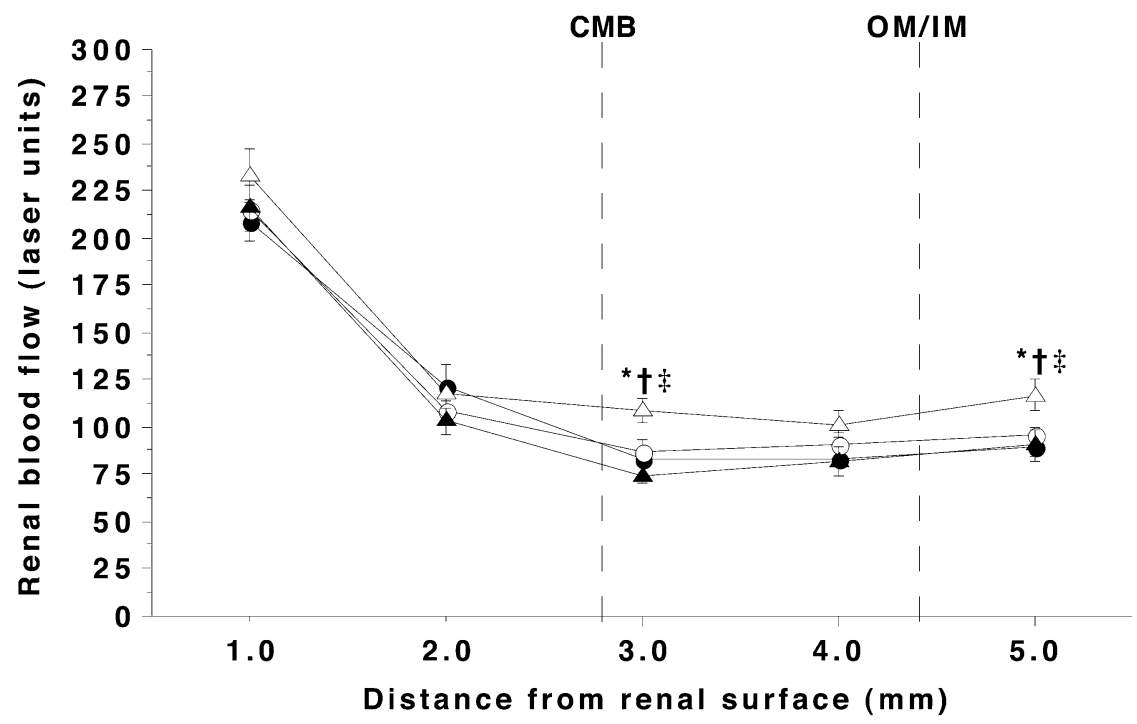

Fig. 1. Blood flow at different depths from the tissue surface in kidneys from control (filled circles) and 4-week-diabetic (filled triangles) male Wistar-Furth rats. Additional groups of control and 4-week-diabetic animals were treated with the aldose reductase inhibitor AL-1576 throughout the experimental period (empty circles and empty triangles respectively).
The anatomical borders between the renal cortex and the medulla (CMB) and between the outer and inner medulla $(\mathrm{OM} / \mathrm{IM})$ are delineated with broken lines. $* p<0.05$ vs nondiabetic control animals; $\dagger p<0.05$ vs 4 -week-diabetic animals; $\ddagger p<0.05$ vs treated non-diabetic animals. The values represent means \pm SEM for eight to fourteen animals

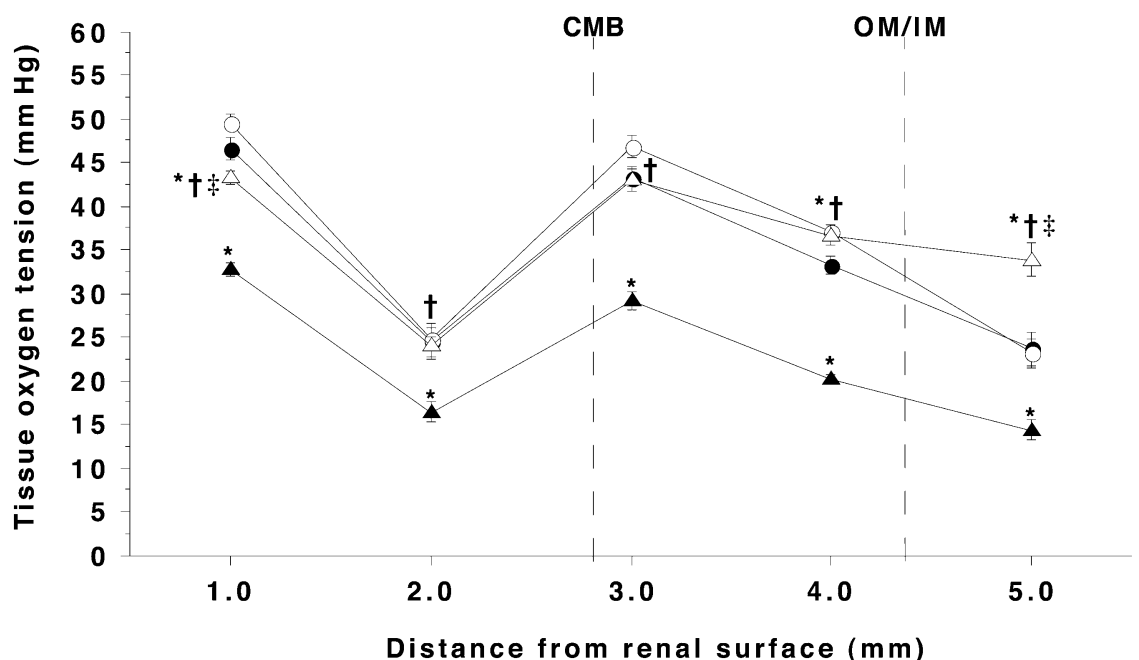

Fig. 2. Tissue oxygen tension at different depths from the tissue surface in kidneys from control (filled circles) and 4-weekdiabetic (filled triangles) male Wistar-Furth rats. Additional groups of control and 4-week-diabetic animals were treated with the aldose reductase inhibitor AL-1576 throughout the experimental period (empty circles and empty triangles respectively). The anatomical borders between the renal cortex and the medulla $(\mathrm{CMB})$ and between the outer and inner medulla $(\mathrm{OM} / \mathrm{IM})$ are delineated with broken lines. ${ }^{*} p<0.05$ vs nondiabetic control animals; $\dagger p<0.05$ vs 4 -week-diabetic animals; $\ddagger p<0.05$ vs treated non-diabetic animals. The values represent means \pm SEM for eight to fourteen animals

ment with AL-1576 had no effect on either the non-diabetic or the diabetic animals' body weights (Table 1). The non-diabetic animals were normoglycaemic (Table 1). In the diabetic animals, blood glucose concentrations increased to $>15 \mathrm{mmol} / \mathrm{l}$ within $48 \mathrm{~h}$ of STZ injection and remained at $\sim 25 \mathrm{mmol} / \mathrm{l}$ throughout the course of the study (Table 1). Treatment with AL-1576 slightly decreased blood glucose concentrations in the diabetic animals. The mean arterial blood pressure, haematocrite, and arterial blood $\mathrm{pH}$ were similar in all rats (Table 1 ).

In all animals, there was a marked blood flow gradient between the cortical and medullary regions (Fig. 1). There was no difference in local blood flow between diabetic and control animals in any of the investigated regions. Treatment of diabetic animals with AL-1576 increased local renal blood flow in comparison with that in both the non-diabetic animals and the corresponding diabetic animals at the distance of 3 and $5 \mathrm{~mm}$ from the renal surface.

Renal tissue oxygen tension was found to be highest in the cortex (depth of $1 \mathrm{~mm}$ ) and in the outer stripe of the outer medulla (depth of $3 \mathrm{~mm}$; Fig. 2). 
Table 2. Cortical and medullary lactate and pyruvate concentrations and lactate : pyruvate ratio in the dialysate from non-diabetic control animals and in animals diabetic for 4 weeks with or without treatment with the aldose reductase inhibitor AL-1576

\begin{tabular}{lccc}
\hline & Control & Diabetes 4 weeks & Diabetes 4 weeks + AL-1576 \\
\hline Cortical lactate concentration $(\mu \mathrm{mol} / \mathrm{l})$ & $104.7 \pm 10.4$ & $146.5 \pm 19.1$ & $146.2 \pm 16.9$ \\
Medullary lactate concentration $(\mu \mathrm{mol} / \mathrm{l})$ & $193.2 \pm 15.6$ & $324.5 \pm 30.6^{\mathrm{a}}$ & $284.2 \pm 49.6$ \\
Cortical pyruvate concentration $(\mu \mathrm{mol} / \mathrm{l})$ & $4.2 \pm 0.6$ & $3.1 \pm 0.5$ & $3.7 \pm 0.7$ \\
Medullary pyruvate concentration $(\mu \mathrm{mol} / \mathrm{l})$ & $13.1 \pm 1.9$ & $13.9 \pm 2.9$ & $19.1 \pm 2.9$ \\
Cortical lactate $:$ pyruvate ratio & $26.7 \pm 2.5$ & $54.5 \pm 9.2^{\mathrm{a}}$ & $55.2 \pm 13.2^{\mathrm{a}}$ \\
Medullary lactate : pyruvate ratio & $17.4 \pm 2.4$ & $35.6 \pm 10.1^{\mathrm{a}}$ & $18.0 \pm 4.6^{\mathrm{b}}$ \\
\hline
\end{tabular}

All values are means \pm SEM for nine to eleven animals. ${ }^{a} p<0.05$ vs control animals; ${ }^{b} p<0.05$ vs untreated diabetic animals. All comparisons were made using ANOVA and, when appropriate, Fisher's protected least significant difference test

There was a pronounced reduction in tissue oxygen tension in the diabetic animals in all investigated sites, but preferentially in the medullary region. Treatment of diabetic animals with AL-1576 prevented this reduction in tissue oxygen tension and, in the inner part of this region, even caused an increase compared with the control group. In the renal cortex, the diabetesinduced reduction in oxygen tension was partially prevented by AL-1576 treatment. Renal oxygen tension in non-diabetic animals was not influenced by AL1576 treatment.

Concentrations of the purine-based metabolites adenosine, inosine and hypoxanthine in the cortical and medullary dialysate were not increased in any of the diabetic animals compared with the non-diabetic animals (data not shown). In all animals, higher lactate and pyruvate concentrations were found in the dialysate obtained from the renal medulla than in that from the renal cortex (Table 2). There were no differences in either lactate or pyruvate levels in the cortical region between diabetic and control rats. However, in the medullary region, the concentration of lactate was increased in the diabetic animals compared with in the non-diabetic animals. Diabetic rats given AL-1576 did not differ in medullary dialysate lactate levels compared with either control or untreated diabetic animals. Pyruvate concentrations in medullary dialysate were similar in all groups.

The lactate : pyruvate ratio was higher in the renal cortex than in the medulla in all groups (Table 2). The diabetic animals had an increased lactate : pyruvate ratio in both the renal cortex and medulla compared with the non-diabetic animals. Daily administration of AL-1576 prevented this increase in lactate : pyruvate ratio in the renal medulla, but not in the renal cortex.

All diabetic animals had increased glucose concentrations in the dialysate obtained from both the renal cortex and the medulla compared with normoglycaemic animals (Fig. 3a). When the ratio between the glucose concentrations in the dialysate obtained from the renal cortex and the medulla was calculated, a decreased ratio in the diabetic animals compared with normoglycaemic animals was observed (Fig. 3b). Diabetic animals given AL-1576 had similar cortical : medullary glucose ratios to untreated diabetic animals, but did not
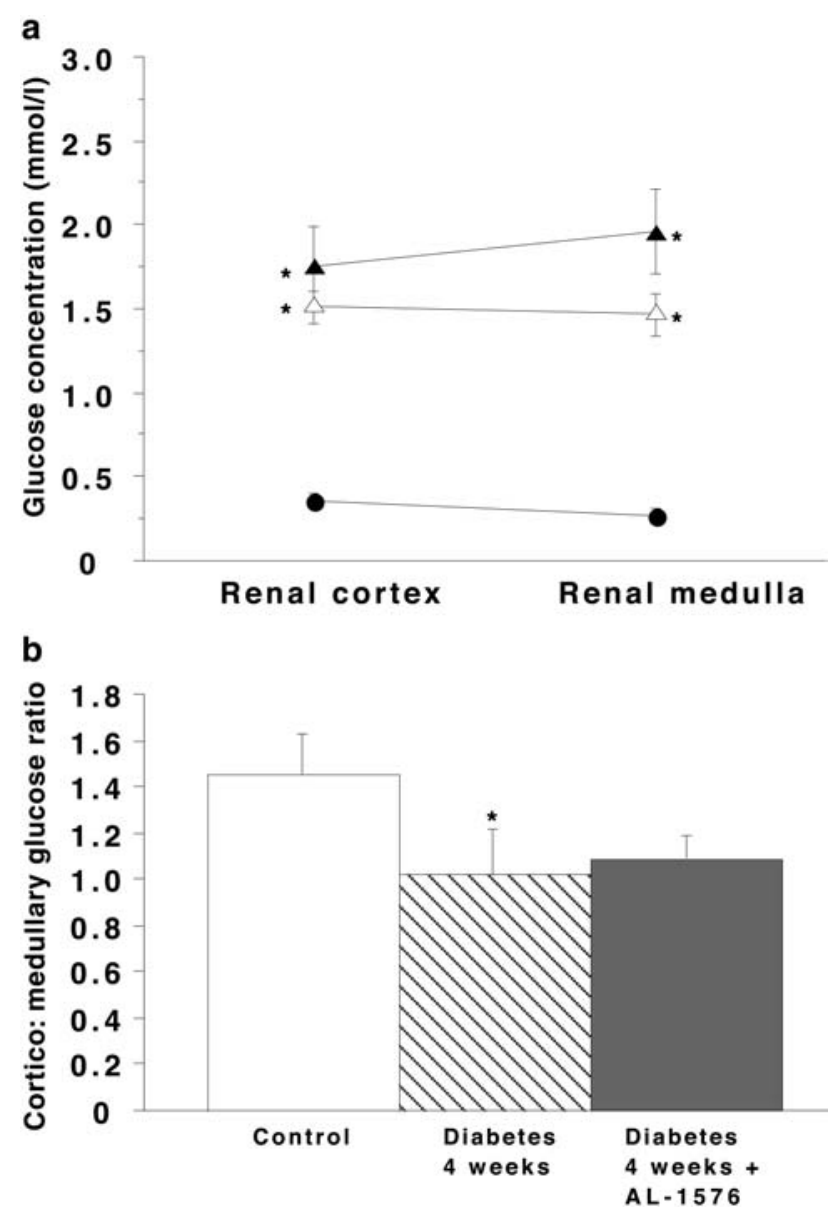

Fig. 3. The upper panel (a) shows glucose concentrations in dialysate obtained from the renal cortex and the renal medulla of control (filled circles) and 4-week-diabetic (filled triangles) male Wistar-Furth rats. An additional group of 4-week-diabetic animals was treated with the aldose reductase inhibitor AL-1576 throughout the course of diabetes (empty triangles). The lower panel (b) shows the ratios between renal cortical and renal medullary dialysate glucose concentrations of control (white bars) and 4-week-diabetic (hatched bars) male Wistar-Furth rats. Ratio values for diabetic animals treated with AL-1576 throughout the course of diabetes are also shown (grey bar). $* p<0.05$ vs non-diabetic control animals. The values represent means \pm SEM for nine to eleven animals 
Table 3. Oxygen consumption in renal cortical and medullary cells from non-diabetic and diabetic rats with or without treatment with the aldose reductase inhibitor AL-1576 throughout the 4-week experimental period

\begin{tabular}{lllll}
\hline & \multicolumn{2}{l}{$\mathrm{O}_{2}$ consumption $\left(\mathrm{nmol} \cdot \mathrm{mg}\right.$ protein $\left.{ }^{-1} \cdot \mathrm{min}^{-1}\right)$} \\
\cline { 2 - 5 } & $\begin{array}{l}\text { Cortical cells } \\
(n=7-10)\end{array}$ & $\begin{array}{l}\text { Cortical cells } \\
+1 \mathrm{mmol} / \mathrm{l} \text { ouabain }(n=7-10)\end{array}$ & $\begin{array}{l}\text { Medullary cells } \\
(n=4-5)\end{array}$ & $\begin{array}{l}\text { Medullary cells } \\
+1 \mathrm{mmol} / 1 \text { ouabain }(n=4-5)\end{array}$ \\
\hline Control & $33.2 \pm 2.4$ & $12.3 \pm 1.8^{\mathrm{c}}$ & $31.1 \pm 4.2$ & $10.0 \pm 3.4^{\mathrm{c}}$ \\
Control + AL-1576 & $25.6 \pm 1.6^{\mathrm{a}}$ & $11.4 \pm 2.4^{\mathrm{c}}$ & $24.5 \pm 3.8$ & $13.3 \pm 3.0^{\mathrm{c}}$ \\
Diabetic & $40.0 \pm 2.9$ & $18.2 \pm 2.1^{\mathrm{c}}$ & $61.7 \pm 5.6^{\mathrm{ad}}$ & $26.3 \pm 5.1^{\mathrm{ac}}$ \\
Diabetic + AL-1576 & $33.2 \pm 3.6$ & $18.1 \pm 2.4^{\mathrm{c}}$ & $28.7 \pm 2.8^{\mathrm{b}}$ & $12.6 \pm 1.8^{\mathrm{bc}}$
\end{tabular}

Results are presented as means \pm SEM. a $p<0.05$ vs control group; ${ }^{\mathrm{b}} p<0.05$ vs corresponding untreated diabetic animals; ${ }^{c} p<0.05$ vs corresponding non-ouabain-treated cells; ${ }^{d} p<0.05$ vs corresponding cortical cells within the same group. All comparisons were made using ANOVA and, when appropriate, Fisher's protected least significant difference test

Table 4. Renal data obtained from the left kidney of non-diabetic control animals and in animals diabetic for 4 weeks with or without treatment with the aldose reductase inhibitor AL-1576

\begin{tabular}{|c|c|c|c|c|}
\hline & $\begin{array}{l}\text { Control } \\
(n=30)\end{array}$ & $\begin{array}{l}\text { Control + AL-1576 } \\
(n=20)\end{array}$ & $\begin{array}{l}\text { Diabetes } 4 \text { weeks } \\
(n=30)\end{array}$ & $\begin{array}{l}\text { Diabetes } 4 \text { weeks } \\
+ \text { AL-1576 }(n=29)\end{array}$ \\
\hline Kidney weight (g) & $1.16 \pm 0.03$ & $0.99 \pm 2^{\mathrm{a}}$ & $1.37 \pm 0.03^{\mathrm{a}}$ & $1.22 \pm 0.03^{\mathrm{bc}}$ \\
\hline Urinary flow rate $(\mathrm{ml} / \mathrm{min})$ & $3.1 \pm 0.4$ & $3.9 \pm 0.6$ & $16.2 \pm 1.8^{\mathrm{a}}$ & $13.0 \pm 1.4^{\mathrm{ac}}$ \\
\hline Osmolal excretion (mosmol/min) & $4.03 \pm 0.44$ & $4.35 \pm 0.49$ & $15.92 \pm .1 .56^{\mathrm{a}}$ & $12.11 \pm 1.04^{\mathrm{abc}}$ \\
\hline Sodium excretion (mmol/min) & $0.21 \pm 0.04$ & $0.10 \pm 0.03$ & $0.29 \pm 0.07$ & $0.90 \pm 0.18^{\mathrm{abc}}$ \\
\hline
\end{tabular}

Results are presented as means \pm SEM. ${ }^{a} p<0.05$ vs control group; ${ }^{\mathrm{b}} p<0.05$ vs untreated 4 -week-diabetic animals; ${ }^{\mathrm{c}} p<0.05$ vs treated control animals. All comparisons were made using

differ statistically from the normoglycaemic animals $(p=0.07)$. The in vitro recovery of purine-based metabolites was $23.5 \pm 5.7 \%$ for all tested substances $(n=4)$. The in vitro recovery for lactate, pyruvate and glucose were $24.2 \pm 1.4,24.5 \pm 2.2$ and $24.9 \pm 2.7 \%$ respectively $(n=4)$ for all investigated substances.

The mean $\mathrm{pH}$ of the cortical tissue was close to 7.4 and lower in the medulla in all investigated animals (Fig. 4). The diabetic animals had a lower medullary $\mathrm{pH}$ than the control animals. Treatment with AL-1576 prevented this decrease. AL-1576 treatment had no effect on renal $\mathrm{pH}$ levels in non-diabetic animals.

Renal medullary, but not renal cortical oxygen consumption was increased in diabetic animals compared with in non-diabetic animals (Table 3). $\mathrm{Na}^{+} / \mathrm{K}^{+}$ ATPase activity, measured as ouabain-sensitive oxygen consumption, accounted for the consumption of $\sim 20 \mathrm{nmol} \cdot \mathrm{mg}$ protein ${ }^{-1} \cdot \mathrm{min}^{-1}$ in cortical cells from both non-diabetic and diabetic animals, as well as in medullary cells from the non-diabetic animals. The ouabain-sensitive oxygen consumption was increased by $75-80 \%$ in the medullary cells from the diabetic animals. Treatment with AL-1576 fully prevented the diabetes-induced increase in total renal medullary oxygen consumption and also slightly decreased total renal cortical oxygen consumption in the non-diabetic animals. AL-1576 also had a separate effect in addi-
ANOVA and, when appropriate, Fisher's protected least significant difference test

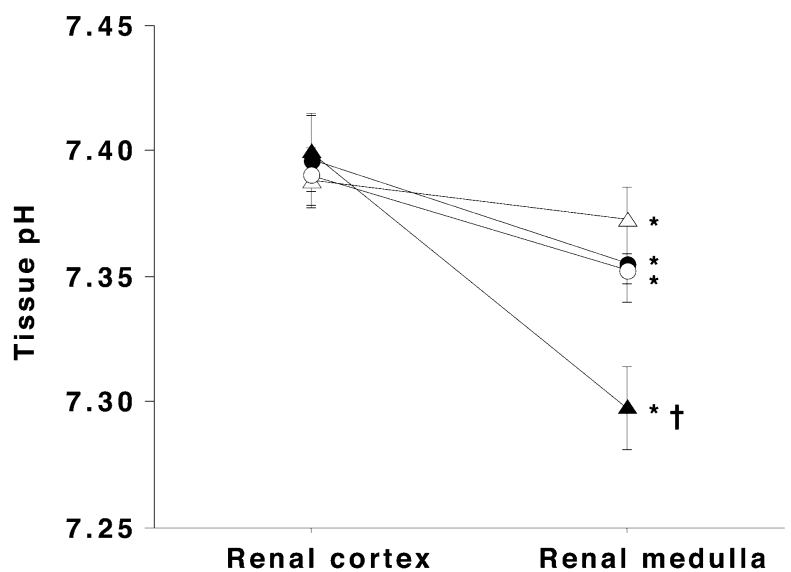

Fig. 4. Tissue $\mathrm{pH}$ obtained from the renal cortex and the medulla of control (filled circles) and 4-week-diabetic (filled triangles) male Wistar-Furth rats. Additional groups of control and 4-week-diabetic animals were treated with the aldose reductase inhibitor AL-1576 throughout the experimental period (empty circles and empty triangles respectively). ${ }^{*} p<0.05$ vs cortex value within the same group; $\dagger p<0.05$ vs non-diabetic control animals within the same region. The values represent means \pm SEM for seven to eight animals

tion to that of ouabain which decreased medullary oxygen consumption in diabetic animals.

Renal weight increased in the diabetic animals (Table 4). Treatment with AL-1576 prevented renal 
growth in diabetic animals and also slightly decreased renal weight in non-diabetic animals. Untreated diabetic animals had similar GFR to control animals (Table 4). The diabetic animals, but not the control animals, treated with AL-1576 displayed a pronounced glomerular hypofiltration. The urine flow rate was 3-4 times higher in diabetic animals than in non-diabetic animals and was unaffected by AL-1576 treatment (Table 4). In the diabetic animals, including the AL-1576-treated group, the urinary excretion of osmotically active particles was at least twice as high as that of the non-diabetic animals (Table 4). Urinary excretion of sodium was similar in untreated diabetic animals, control animals and treated control animals, whilst diabetic animals treated with AL-1576 had clearly elevated excretion (Table 4). The urinary excretion of potassium was similar in all investigated groups (Table 4).

\section{Discussion}

It has previously been suggested that aggravated low oxygen tension in the renal medulla may cause progression of nephropathy $[5,6]$. In view of our previous [8] and present results with markedly decreased renal tissue oxygen tension during chronic hyperglycaemia, we conducted separate experiments applying microdialysis to assess the regional interstitial metabolic environment in vivo. Increased lactate levels were observed in the renal medulla of the diabetic animals. Despite the fact that no systemic acidosis was present in any of the investigated animals, the diabetic animals displayed a pronounced medullary decrease in tissue $\mathrm{pH}$. Most likely, this is a consequence of the observed increased medullary lactate concentration. Blood $\mathrm{pH}$ was slightly lower than cortical tissue $\mathrm{pH}$, probably due to a combined effect of net production of bicarbonate and differences in the composition of the buffer systems in the two compartments.

An altered $\mathrm{pH}$ in the renal medulla may affect the oxygen delivery to this region since the blood supply is derived through the vasa recta, which is a countercurrent system. Osmolytes, preferentially sodium, potassium and urea, are re-circulated and kept in the medulla while oxygen is shunted and transported in the other direction. This results in low oxygen delivery to the medullary structures even under normal conditions [5]. Excessive formation of hydrogen ions in the renal medulla is likely to increase the shunting of oxygen in the vasa recta even further. This may account for at least part of the decrease in medullary tissue oxygen tension found in the diabetic animals. Notably, the altered $\mathrm{pH}$ was not associated with increased concentrations of purine-based metabolites (adenosine, inosine and hypoxanthine). These findings therefore do not support the hypothesis of manifest medullary hypoxia in diabetes, since changes in pu- rine-based metabolites and lactate should occur simultaneously in response to oxygen deprivation. It is, however, reasonable to believe that restricted oxygen availability reduces the ability of the medullary cells to cope with increased stress, i.e. situations requiring increased production of ATP and concomitant oxygen consumption. Indeed, progression of experimental diabetic nephropathy is significantly accelerated if renal oxygen supply is further affected [19].

The concentrations of lactate were related to pyruvate concentrations by calculating the ratio. A marked increase in the lactate : pyruvate ratio was found in the 4-week-diabetic animals in both the renal cortex and the medulla. Imbalance in the lactate : pyruvate ratio may reflect hypoxia. However, during hyperglycaemia, similar changes have been shown to occur due to overactivity in the polyol pathway, causing an increased reduction rate of $\mathrm{NAD}^{+}$to $\mathrm{NADH}$, and thereby an increased probability that the lactate : pyruvate equilibrium re-oxidises NADH [2]. Hyperglycaemiainduced mitochondrial production of ROS has been shown to induce activation of the polyol pathway [20]. Inhibition of aldose reductase activity has previously been used to inhibit glucose metabolism through the polyol pathway $[21,22,23]$. In the present study we used AL-1576, which in comparative studies with other aldose reductase inhibitors has been shown to be both highly potent and selective and to lack antioxidant effects [24, 25]. Treatment with AL-1576 throughout the course of diabetes prevented the increase in lactate : pyruvate ratio in the renal medulla and also normalised medullary $\mathrm{pH}$. This suggests that polyol pathway overactivity caused the observed metabolic disturbances in the renal medullary region, resulting in increased lactate concentration and concomitant decreased $\mathrm{pH}$. The reason for the increased lactate : pyruvate ratio in the renal cortex of the diabetic animals, which was unaffected by AL-1576 treatment, remains to be determined.

The diabetes-induced decrease in medullary tissue oxygen tension was also prevented by AL-1576 treatment, suggesting an involvement of the polyol pathway. One potential mechanism is a change in oxygen-haemoglobin dissociation, occurring as a result of increased lactate concentration and concomitant decreased $\mathrm{pH}$ in the renal medulla in diabetic animals (see above). However, an increased renal cellular oxygen consumption has previously been reported in vitro during the early onset of diabetes mellitus [8, 17]. This was partly ascribed to increased tubular load of sodium, as a result of glomerular hyperfiltration [17]. In the present work, however, we chose to study diabetic animals when the initial diabetes-induced glomerular hyperfiltration, known to exist in this rat strain [26], was no longer present. The reduced renal oxygen tension and increased renal cellular oxygen consumption were also independent of GFR [8]. A perhaps more plausible explanation is therefore that the in- 
creased glucose load to the proximal tubular cells enhances the flux through the $\mathrm{Na}^{+} /$glucose co-transporters [17]. As a result, $\mathrm{Na}^{+} / \mathrm{K}^{+}$-ATPase up-regulates and thus increases oxygen consumption $[17,27]$. This explanation is also supported by results showing that the ouabain-sensitive inhibition of oxygen consumption was increased in the medullary cells of the diabetic animals.

Treatment of diabetic animals with the aldose reductase inhibitor AL-1576 prevented the hyperglycaemia-induced increase in renal oxygen consumption. The markedly increased urinary sodium excretion in AL-1576-treated diabetic animals indicates that this aldose reductase inhibitor, directly or indirectly, inhibited $\mathrm{Na}^{+} / \mathrm{K}^{+}$-ATPase activity and thereby altered the oxygen consumption. Moreover, the diabetic animals treated with AL-1576 had a lower GFR than the untreated diabetic animals, which may have contributed to the reduction of ouabain-sensitive oxygen consumption. The aldose reductase inhibitor, however, also seemed to have the additional effect of decreasing renal oxygen consumption, as well as the inhibitory influence on the $\mathrm{Na}^{+} / \mathrm{K}^{+}$-ATPase activity, since AL1576 further decreased oxygen consumption in the ouabain-treated medullary cells. The exact mechanism for this effect remains to be determined. Enhanced expression of uncoupling protein-2 has been found to occur during chronic hyperglycaemia [27]. Diabetes is also generally associated with increased gluconeogenesis [28] and fatty acid metabolism [29]. Indeed, total oxygen consumption has been shown to increase by $10-12 \%$ in diabetic subjects [30]. In the inner medullary region, the tissue oxygen tension of AL-1576treated animals was even increased compared with the non-diabetic animals, which was paralleled by a tendency of increased blood perfusion in this part of the kidney. The reason for the decreased GFR and increased medullary blood perfusion following AL-1576 treatment in diabetic animals is unknown, but the combination of these findings suggests dilation of the efferent arteriole. It is interesting to note that AL-1576 had little effect on control animals, except to decrease renal weight, while diabetic animals displayed increased medullary blood flow, oxygen tension and sodium excretion as well as reduced GFR. These results indicate that AL-1576 might have physiological effects in hyperglycaemic animals. The long-term effects of AL-1576-induced changes for renal function still remain to be determined.

The kidney weight increased in untreated diabetic animals. This has previously been ascribed to several factors, predominantly 1,2-diacyl-sn-glycerol (DAG) [2] and IGF-1 [31, 32], but also, for example, to TGF- $\beta$ [33], angiotensin II [34] and atrial natriuretic peptide [35]. In the present study, kidney weight was reduced following treatment with AL-1576. Inhibition of hyperglycaemia-induced aldose reductase activity is known to inhibit the synthesis of DAG and thus in- hibit protein kinase $\mathrm{C}(\mathrm{PKC})$ activity [2]. Any direct effects of aldose reductase inhibitors on the expression of IGF-1 or its receptors have not, to our knowledge, been described. However, the effects of IGF-1 and the expression of TGF- $\beta$ have been shown to be influenced by PKC activity [36, 37]. Interestingly, hyperglycaemia-induced increase in PKC activity can be reduced by aldose reductase inhibitors [38, 39], although other studies have reported ineffectiveness of such treatment [40].

Both renal cortical and medullary dialysate glucose concentrations were markedly higher in the diabetic animals than in the non-diabetic animals. Under normoglycaemic conditions, almost $100 \%$ of the filtrated glucose is actively re-absorbed in the proximal tubuli. Therefore, the cortico-medullary glucose ratio in normoglycaemic animals is $>1$. In comparison, in the diabetic animals the $K_{\mathrm{m}}$ for the glucose transporter in the proximal tubuli is exceeded, resulting in glucosuria. In addition, concentrations of the glomerular filtrate along the tubuli further increase medullary glucose concentrations. A combined effect of these mechanisms is an increased exposure of glucose to the medullary cells. Although diabetic animals treated with AL-1576 had a slightly lower blood glucose concentration than the untreated diabetic animals, this difference was too marginal to be reflected in the glucose concentrations in the renal tissue from the two groups.

In conclusion, metabolic changes in experimental diabetes mellitus were predominately observed in the scarcely studied renal medulla. These changes, with decreased oxygen tension, increased oxygen consumption and enhanced lactate formation, resulting in a decreased tissue $\mathrm{pH}$, were all mediated by the polyol pathway and could be prevented by inhibiting the enzymatic activity of aldose reductase.

Acknowledgements. This study was supported by the Swedish Diabetes Association, the Swedish Juvenile Diabetes Foundation, the Knut and Alice Wallenberg Foundation, the Anér Foundation, the Selander Foundation, the Ernfors' Family Foundation, the Konsul Ture Carlsson Foundation, the Swedish Medical Society, the Marcus and Amalia Wallenberg Foundation, the Lars Hiertas Memorial Foundation, the Research Foundation of Apotekare Hedbergs, the Harald and Greta Jeansson Foundation, the Swedish Heart Lung Foundation and the Swedish Medical Research Council (9940, 10840 and 14033). Alcon Laboratories (Forth Worth, Tex., USA) kindly provided the aldose reductase inhibitor AL-1576. The excellent technical assistance of Angelica Fasching, Astrid Nordin and Lena Nallmo is gratefully acknowledged.

\section{References}

1. The Diabetes Control and Complications Trial Research Group (1993) The effect of intensive treatment of diabetes on the development and progression of long-term complications in insulin-dependent diabetes mellitus. N Engl J Med 329:977-986 
2. Williamson JR, Chang K, Frangos M et al. (1993) Hyperglycemic pseudohypoxia and diabetic complications. Diabetes 42:801-813

3. Cameron NE, Cotter MA (1997) Metabolic and vascular factors in the pathogenesis of diabetic neuropathy. Diabetes 46 [Suppl 2]:S31-S37

4. Linsenmeier RA, Braun RD, McRipley MA et al. (1998) Retinal hypoxia in long-term diabetic cats. Invest Ophthalmol Vis Sci 39:1647-1657

5. Brezis M, Rosen S (1995) Hypoxia of the renal medulla its implication for disease. New Engl J Med 332:647-655

6. Zhong Z, Arteel GE, Connor HD et al. (1998) Cyclosporin A increases hypoxia and free radical production in rat kidneys: prevention by dietary glycine. Am J Physiol 275:F595-F604

7. Brezis M, Rosen S, Silva P, Epstein FH (1984) Renal ischemia: a new perspective. Kidney Int 26:375-383

8. Palm F, Cederberg J, Hansell P, Liss P, Carlsson PO (2003) Reactive oxygen species cause diabetes-induced decrease in renal oxygen tension. Diabetologia 46:1153-1160

9. Nishikawa T, Edelstein D, Brownlee M (2000) The missing link: a single unifying mechanism for diabetic complications. Kidney Int 58 [Suppl 77]:S26-S30

10. Dyck PJ, Windebank A, Yasuda H, Service FJ, Rizza R, Zimmerman B (1985) Diabetic neuropathy. Adv Exp Med Biol 189:305-320

11. Stevens MJ, Dananberg J, Feldman EL et al. (1994) The linked roles of nitric oxide, aldose reductase and $(\mathrm{Na}+\mathrm{K}+)$-ATPase in the slowing of nerve conduction in the streptozotocin diabetic rat. J Clin Invest 94:853-859

12. Van den Enden MK, Nyengaard JR, Ostrow E, Burgan JH, Williamson JR (1995) Elevated glucose levels increase retinal glycolysis and sorbitol pathway metabolism. Implications for diabetic retinopathy. Invest Ophthalmol Vis Sci 36:1675-1685

13. Liss P, Nygren A, Revsbech NP, Ulfendahl H (1997) Intrarenal oxygen tension measured by a modified Clark electrode at normal and low blood pressure and after injection of x-ray contrast media. Pflugers Arch 434:705-711

14. Carlsson PO, Nordin A, Palm F (2003) pH is decreased in transplanted rat pancreatic islets. Am J Physiol Endocrinol Metab 284:E499-E504

15. Wikstrom G, Ronquist G, Nilsson S, Maripu E, Waldenstrom A (1995) Continuous monitoring of energy metabolites using microdialysis during myocardial ischaemia in the pig. Eur Heart J 16:339-347

16. Wikstrom BG, Ronquist G, Waldenstrom A (1995) Dynamics of myocardial metabolism in the preconditioned porcine heart studied using continuous microdialysis. Eur Heart J 16:563-569

17. Korner A, Eklof AC, Celsi G, Aperia A (1994) Increased renal metabolism in diabetes. Mechanism and functional implications. Diabetes 43:629-633

18. Koivisto A, Pittner J, Froelich M, Persson AE (1999) Oxygen-dependent inhibition of respiration in isolated renal tubules by nitric oxide. Kidney Int 55:2368-2375

19. Melin J, Hellberg O, Akyurek LM, Kallskog O, Larsson E, Fellstrom BC (1997) Ischemia causes rapidly progressive nephropathy in the diabetic rat. Kidney Int 52:985-991

20. Nishikawa T, Edelstein D, Du XL et al. (2000) Normalizing mitochondrial superoxide production blocks three pathways of hyperglycaemic damage. Nature 404:787-790

21. Greene DA, Chakrabarti S, Lattimer SA, Sima AA (1987) Role of sorbitol accumulation and myo-inositol depletion in paranodal swelling of large myelinated nerve fibers in the insulin-deficient spontaneously diabetic bio-breeding rat. Reversal by insulin replacement, an aldose reductase inhibitor, and myo-inositol. J Clin Invest 79:1479-1485
22. Robison WG Jr, Kador PF, Kinoshita JH (1983) Retinal capillaries: basement membrane thickening by galactosemia prevented with aldose reductase inhibitor. Science 221:1177-1179

23. Yue DK, Hanwell MA, Satchell PM, Turtle JR (1982) The effect of aldose reductase inhibition on motor nerve conduction velocity in diabetic rats. Diabetes 31:789794

24. Griffin BW, McNatt LG, Chandler ML, York BM (1987) Effects of two new aldose reductase inhibitors, AL-1567 and AL-1576, in diabetic rats. Metabolism 36:486-490

25. Thomas T, Rauscher F, Sanders R, Veltman J, Watkins JB 3rd (2000) Effects of aldose reductase inhibitors on antioxidant defense in rat and rabbit liver. Toxicol Sci 53:145-149

26. Palm F, Liss P, Farsching A, Hansell P, Carlsson P-O (2002) Transient glomerular hyperfiltration in the streptozotocin-diabetic Wistar Furth rat. Upsala J Med Sci 106:175-182

27. Baines A, Ho P (2002) Glucose stimulates O2 consumption, NOS, and $\mathrm{Na} / \mathrm{H}$ exchange in diabetic rat proximal tubules. Am J Physiol Renal Physiol 283:F286-F293

28. Peroni O, Large V, Diraison F, Beylot M (1997) Glucose production and gluconeogenesis in postabsorptive and starved normal and streptozotocin-diabetic rats. Metabolism 46:1358-1363

29. Guder WG, Schmolke M, Wirthensohn G (1992) Carbohydrate and lipid metabolism of the renal tubule in diabetes mellitus. Eur J Clin Chem Clin Biochem 30:669-674

30. Horstman P (1951) The oxygen consumption in diabetes mellitus. Acta Med Scand 139:326-330

31. Bach LA, Jerums G (1990) Effect of puberty on initial kidney growth and rise in kidney IGF-I in diabetic rats. Diabetes 39:557-562

32. Haylor J, Hickling H, El Eter E et al. (2000) JB3, an IGF-I receptor antagonist, inhibits early renal growth in diabetic and uninephrectomized rats. J Am Soc Nephrol 11:20272035

33. Kanda S, Igawa T, Taide M et al. (1993) Transforming growth factor-beta in rat kidney during compensatory renal growth. Growth Regul 3:146-150

34. Wolf G, Ziyadeh FN (1997) The role of angiotensin II in diabetic nephropathy: emphasis on nonhemodynamic mechanisms. Am J Kidney Dis 29:153-163

35. Logan JL, Michael UF (1994) Atrial natriuretic peptide suppresses compensatory renal growth in rats. J Am Soc Nephrol 4:2016-2022

36. Murphy M, McGinty A, Godson C (1998) Protein kinases $\mathrm{C}$ : potential targets for intervention in diabetic nephropathy. Curr Opin Nephrol Hypertens 7:563-570

37. Yano K, Bauchat JR, Liimatta MB, Clemmons DR, Duan C (1999) Down-regulation of protein kinase C inhibits insulin-like growth factor I-induced vascular smooth muscle cell proliferation, migration, and gene expression. Endocrinology 140:4622-4632

38. Ishii H, Tada H, Isogai S (1998) An aldose reductase inhibitor prevents glucose-induced increase in transforming growth factor-beta and protein kinase $\mathrm{C}$ activity in cultured mesangial cells. Diabetologia 41:362-364

39. Nakamura J, Kasuya Y, Hamada Y et al. (2001) Glucoseinduced hyperproliferation of cultured rat aortic smooth muscle cells through polyol pathway hyperactivity. Diabetologia 44:480-487

40. Nakamura J, Kato K, Hamada Y et al. (1999) A protein kinase C-beta-selective inhibitor ameliorates neural dysfunction in streptozotocin-induced diabetic rats. Diabetes 48:2090-2095 